\title{
Chemical and sensory characteristics of Gaglioppo wines obtained from grapes grown under two different water regimes
}

\author{
A. Bosso ${ }^{1}$, M. Guaita ${ }^{1}$, L. Panero ${ }^{1}$, S. Motta ${ }^{1}$, M. Petrozziello ${ }^{1}$, C. Tsolakis ${ }^{1}$, and L. Sansone ${ }^{2}$ \\ ${ }^{1}$ CREA - Consiglio per la Ricerca in Agricoltura e l'Analisi dell'Economia Agraria - Centro di Ricerca Viticoltura ed Enologia, Via \\ P. Micca 35, Asti, Italy \\ ${ }^{2}$ CREA - Consiglio per la Ricerca in Agricoltura e l'Analisi dell'Economia Agraria - Centro di Ricerca Viticoltura ed Enologia, Viale \\ XXVIII Aprile 26, Conegliano (TV), Italy
}

\begin{abstract}
Climate change can affect the crops production capacity and modify the water requirements in the different regions of the world. In particular, in southern Europe and in the Mediterranean region the vegetative cycle of plants will take place in a warmer and drier period, with the consequent increase in vegetative activity, transpiration rate, and water consumption. In the case of vine, the rationalization of water resource needs a deep knowledge of the complex relationships between climate, soil, water availability and grape variety, in order to preserve the high quality regional wine productions. In the Cirò DOC area (Calabria), the effect of irrigation, prolonged until maturity, on the polyphenolic content of the grapes was studied with the Gaglioppo red grapes variety, in order to verify whether a moderate post-veraison water supply could favour the completion of phenolic maturation. Two different water regimes were compared in the vineyard, and the physicochemical composition, the polyphenolic and aromatic profiles and the sensory characteristics of the resulting wines were studied. The study confirmed that the climatic variability of the different vintages can influence both the vegetative-productive activity of vines and the effect of water supplies.
\end{abstract}

\section{Introduction}

Climate change, besides affecting the crops production capacity [1], will also result in a substantial modification of the water requirements, also in complex ways, in the different regions of the world. Important transformations in the current climate are expected in southern Europe and in those areas of the Mediterranean region where an increase in temperature is forecasted, especially in summer with an increase in heat waves and a marked decrease in rainfalls, with a consequent decrease in water availability and intensification of increasingly severe periods of water scarcity [2], generally foreseeing an intensification of extreme events [3]. Consequently, from studies conducted on the adaptation of the vine to climate change, the vegetative cycle will take place in a warmer and drier period [4], during which the higher temperatures can have different influences on the plants; among these, the increase in vegetative activity and therefore in the transpiration rate $[5,6]$, with a consequent increase in water consumption that will be only partially satisfied by natural inputs, pushing winegrowers to constantly use water complements to fill the rainfall deficit. With such perspectives, the maximum rationalization of water resource management becomes necessary, due also to the greater knowledge of the vine adaptive mechanisms and its actual physiological needs. Considering the reduced water availability, a more sustainable management of irrigation needs, therefore, to deepen the studies on the complex relationships between climate, soil, water availability and grape variety, thus aiming to preserve, if not to improve, the high quality achieved in regional wine productions.
For this reason, we wanted to verify in the Cirò DOC area (Calabria), with the Gaglioppo red grapes variety, the effect of irrigation, prolonged until maturity, on the polyphenolic content of the grapes, which is generally penalized by water stress conditions [7]. In particular, a moderate post-veraison water supply could enhance both the synthesis and accumulation dynamics of the soluble solids, and the completion of phenolic maturation. The work concerned the comparison between the physicochemical composition, the polyphenolic and aromatic profiles and the sensory characteristics of wines obtained from grapes grown under 2 different water regimes and, during alcoholic fermentation, subjected to 2 different fermentative maceration techniques (with or without seeds removal).

\section{Materials and methods}

In the production area of the Cirò DOC (Strongoli, KR), in the 2011 and 2012 vintages the behavior of the Gaglioppo variety was investigated in an experimental vineyard of the Ceraudo Winery by applying two different water regimes. The FI thesis consisted in controlled irrigation from flowering to veraison with the vines in conditions of moderate stress $\left(\Psi_{\text {stem }} \geq-0.8 \mathrm{MPa}\right.$ ), while the FM thesis extended irrigation to maturation, keeping the vines at a water content of $0.8 \mathrm{MPa}$, in order to verify whether this prolongation of the irrigation could favor the phenolic maturation processes. Part of the experimental vineyard was divided into three randomized blocks, in each of which the two theses were divided. Irrigation was performed with an above-ground pressure irrigation 


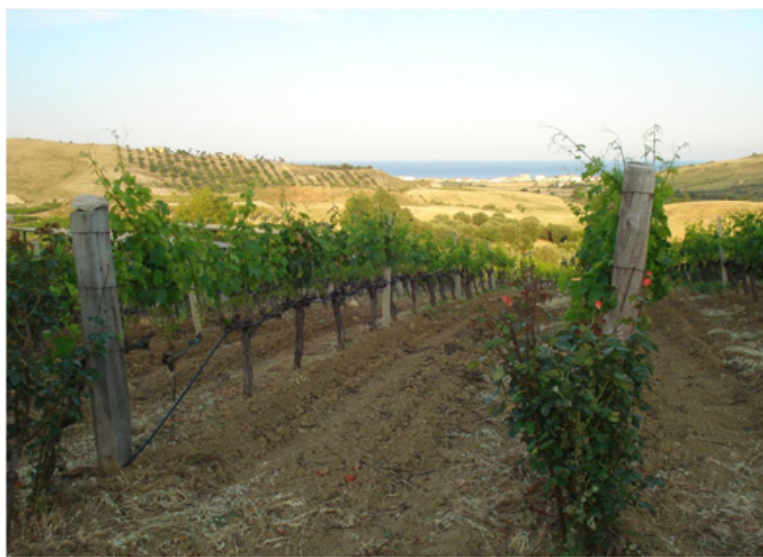

Picture 1. Experimental vineyard of the Ceraudo Winery.

system with a sprinkler wing suspended about $70 \mathrm{~cm}$ from the ground and sprinkler-type sprayers spaced $120 \mathrm{~cm}$ apart: actually, there was a sprinkler for each vine since the 15-year-old vineyard, trained with spurred cordon, had a planting density of $2.50 \mathrm{~m} \times 1.20 \mathrm{~m}$, equal to about 3300 vines/ha (Picture 1 ).

Single leaf gas exchange was measured in 2012 and 2013 with the CIRAS 2 portable measurement system (PPSYSTEMS Europe, Herts, UK). The measures were performed by setting the air flow at $320 \mathrm{~mL} / \mathrm{min}$ and the $\mathrm{CO}_{2}$ concentration at about $400 \mathrm{ppm}$, with environmental relative humidity and in conditions of photosynthetically active saturating radiation (PAR $1800 \mu \mathrm{mol} \mathrm{m}^{2} \mathrm{~s}^{-1}$ ). $\mathrm{CO}_{2}$ assimilation (A), transpiration (E) and stomatal conductance $(\mathrm{gs})$ were obtained on the basis of the relative concentrations of $\mathrm{CO}_{2}$ and $\mathrm{H}_{2} \mathrm{O}$ (difference between inlet and outlet), while the intrinsic efficiency of the water use (WUEi) was derived from the ratio between A and gs.

For each thesis, 12 main leaves were selected, located between the $5^{\text {th }}$ and $7^{\text {th }}$ node above the distal cluster, on the main shoot, and these leaves were used for all subsequent photosynthetic measures carried out in the morning (8:00-11:00). The water status of the vines was monitored by measuring the stem water potential $\left(\Psi_{\text {stem }}\right)$ with the Scholander pressure chamber (Skye Instruments), simultaneously with the gas exchange measurements; for each thesis 18 main leaves were used, chosen in the middle of the shoot.

At harvest, the production of 10 vines per block was evaluated for each thesis, thus obtaining the unitary production and the average weight of the cluster and the berries. The grapes of the two theses were vinified separately (2011 and 2012 vintages). Each thesis was subjected to 2 different winemaking techniques: the delayed extraction of anthocyanins [8] was applied with or without seeds removal, which was performed (when applied) during the délestage, after the achievement of $6 \%$ alcohol; fermentative maceration lasted 8 days for all theses.

The wines were analyzed and subjected to sensory analysis after 9 months of aging in steel tanks. The main chemical parameters (alcohol content, free and total $\mathrm{SO}_{2}, \mathrm{pH}$ and titratable acidity) were determined according to EEC methods [9]; organic acids were determined by HPLC [10]; the phenolic composition (total anthocyanins, total flavonoids, proanthocyanidins, flavans reactive with vanillin) was determined according to [11]; wine color was determined by spectrophotometry (absorbance at 420 and $520 \mathrm{~nm}$, p.o. $1 \mathrm{~mm}$ ). The content of condensed tannins (proanthocyanidins), their average degree of polymerization and their monomer profile were determined by HPLC with the phloroglucinolysis technique $[12,13]$. The aromatic profile of wines was determined according to [18].

Regarding the sensory analysis, the wines were subjected to the ranking test, separately for each vintage: the tasters were asked to classify the wines according to an increasing order of intensity for color, fruity aroma, softness and the bitter taste, and to an increasing order of pleasantness for the olfactory, gustatory and global characteristics.

\section{Results}

Figures 1a and 1d clearly show the close relationship between the trend of net photosynthesis (Pn) and the water status of plants $\left(\Psi_{\text {stem }}\right)$ for both theses.

In fact, at the first measurement at the beginning of July (DOY 186), in optimal water conditions, the carbonic assimilation reached values between $8 \mu \mathrm{mol} \mathrm{CO}_{2} \mathrm{~m}^{2} \mathrm{~s}^{-1}$ for FI and $10 \mu \mathrm{mol} \mathrm{CO} \mathrm{CO}_{2} \mathrm{~s}^{-1}$ for FM. These are not high values, but satisfactory when considering that the leaf temperatures were already higher than $35^{\circ} \mathrm{C}$, as shown in Fig. 1a, and that the month of July 2012 had the highest value of the Winkler index (Fig. 3).

The net photosynthesis of FM was always higher, sometimes slightly, than the Pn of FI (Fig. 1a); the trend, for both theses, was progressively decreasing until the last measurement at the end of August (DOY 243), when values were rather low and included between about $2 \mu \mathrm{mol}$ $\mathrm{CO}_{2} \mathrm{~m}^{2} \mathrm{~s}^{-1}$ for the thesis irrigated until veraison (FI) and $3 \mu \mathrm{mol} \mathrm{CO}_{2} \mathrm{~m}^{2} \mathrm{~s}^{-1}$ for the thesis with prolonged irrigation until maturation (FM). This was due both to the progressive increase of water stress $\left(\Psi_{\text {stem }}\right)$, more evident at the last two measurements for FI (Fig. 1d), and to the aging of the leaves.

The high environmental temperatures (Fig. 2) and the thermal sums (Fig. 3) also conditioned the transpiration activity, which was slightly higher for FI and which, in parallel with photosynthesis, decreased for both theses until the end of August (Fig. 1b) with the increase of the water potential of the stem $\Psi_{\text {stem }}$ (Fig. 1d) [14].

Figure 1c shows how the intrinsic efficiency of water use (WUEi), expressed by the $\mathrm{P}_{\mathrm{n}} / \mathrm{g}_{\mathrm{s}}$ ratio, was always higher for FM than for FI, due to the greater assimilative capacity associated with a lower transpiration activity that reflected the limited stomatal conductance $\left(\mathrm{g}_{\mathrm{s}}\right)$ (data not reported). The photosynthetic activity in 2012, as in 2013 (data not reported), was not high, but more than sufficient as evidenced by the production results obtained. Its values and its trend fully reflected the environmental climatic conditions, particularly the high temperatures of both the air and the leaf blade, and the hydration status of the vines which, especially towards the end of the vegetative season, was rather low with stem water potentials close to $-1.3 \mathrm{Mpa}$ for both theses.

The grapes production per vine in 2011 (Table 1), number of buds being equal, was similar for the two theses: $1.78 \mathrm{~kg}$ for FM and $1.70 \mathrm{~kg}$ for FI. Similar values were obtained also for the average weight of the bunch, slightly 

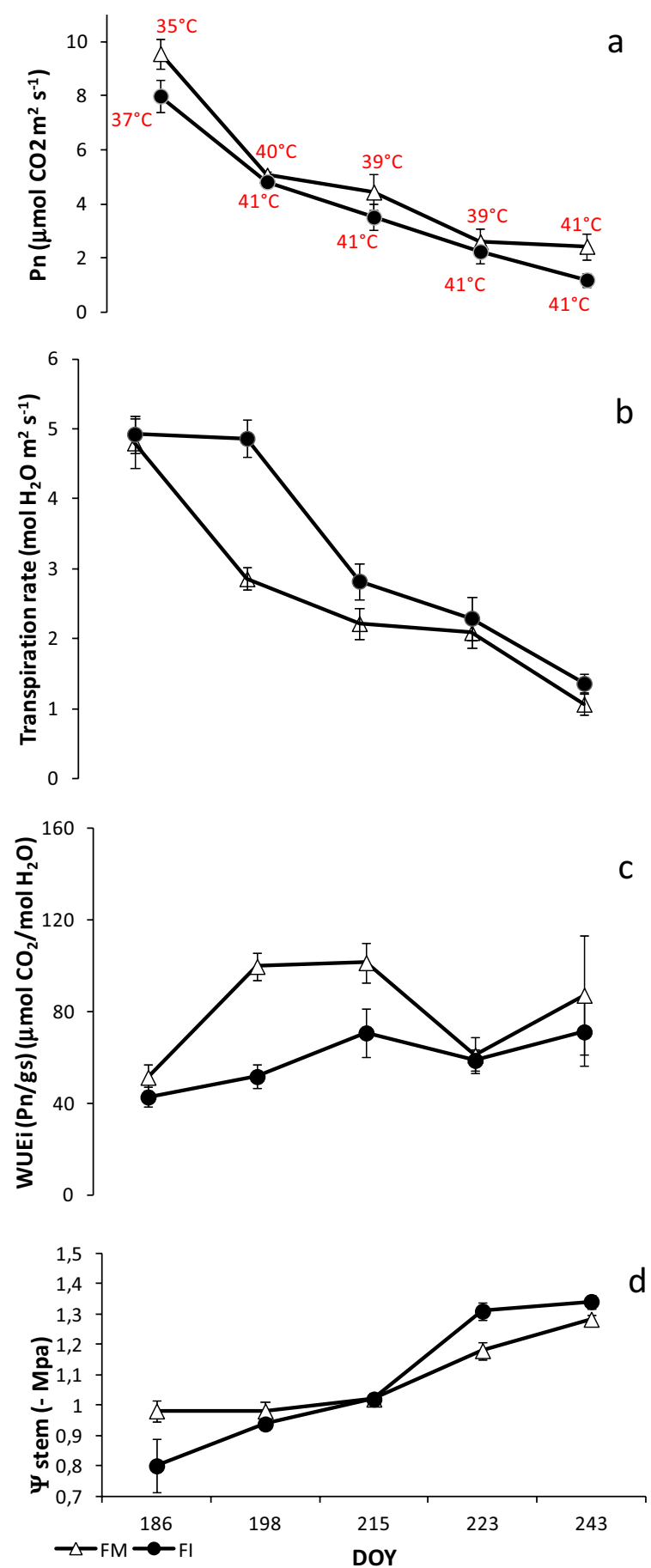

Figure 1. Trend of gas exchanges and water potential in 2012. Mean data \pm s.e. of 3 replicates (Pn, T e WUEi) and 4 replicates $\left(\Psi_{\text {stem }}\right)$. a: net photosynthesis $(\mathrm{Pn})$. The values along the line indicate the temperature of the leaf blade $\left({ }^{\circ} \mathrm{C}\right)$. b: leaf transpiration $(\mathrm{T}$ ). c: intrinsic efficiency of water use (WUEi) from the ratio $P_{n} / g_{s}$. d: water status of the vines expressed as the water potential of the stem $\left(\Psi_{\text {stem }}\right)$.

higher than $180 \mathrm{~g}$ for both theses, and for the average weight of the berry (1.96 $\mathrm{g}$ for FM and $2.04 \mathrm{~g}$ for FI). The differences in grapes production per vine slightly increased in 2012, with values of $2 \mathrm{~kg}$ and $1.8 \mathrm{~kg}$ respectively for FM and FI (Table 1).

Among other factors, number of buds being equal, this difference was related to the weight of the clusters that

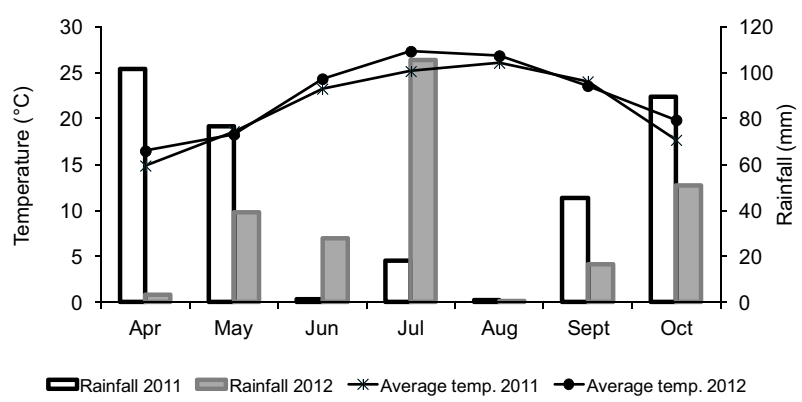

Figure 2. Rainfalls and average monthly temperature trends of the two years.

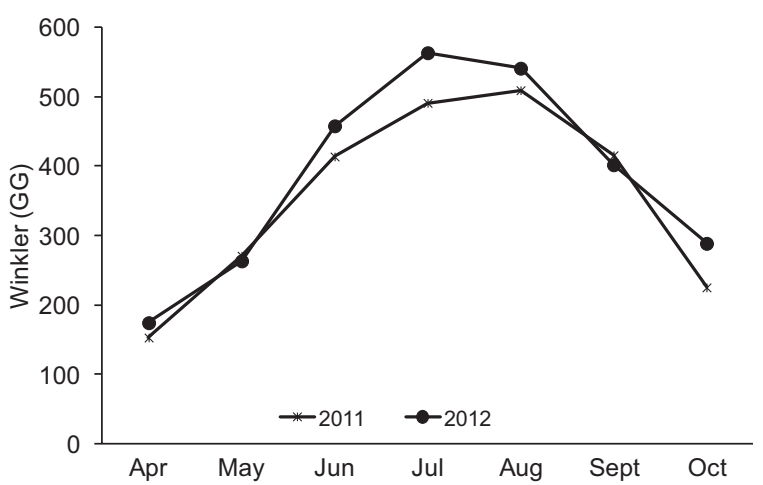

Figure 3. Trend of the Winkler index in 2011 and 2012.

Table 1. Productive data for the 2011 and 2012 vintages. On the line and by year, different letters indicate significant differences between the mean values for $P<0.05$ (Duncan Test).

\begin{tabular}{l|cc|cc|cc|cc}
\hline Variables & \multicolumn{3}{|c|}{2011} & \multicolumn{3}{c}{2012} \\
& \multicolumn{2}{|c|}{ FI } & FI & FI & FI \\
\hline Bunch/vine $\left(\mathrm{n}^{\circ}\right)$ & 9 & $\mathrm{a}$ & 10 & $\mathrm{a}$ & 12 & $\mathrm{a}$ & 11 & $\mathrm{a}$ \\
grape/vine $(\mathrm{kg})$ & 1.7 & $\mathrm{a}$ & 1.8 & $\mathrm{a}$ & 1.8 & $\mathrm{~b}$ & 2.0 & $\mathrm{a}$ \\
ABunchW $(\mathrm{g})$ & 183.0 & $\mathrm{a}$ & 184.0 & $\mathrm{a}$ & 148.0 & $\mathrm{~b}$ & 202.0 & $\mathrm{a}$ \\
ABerryW $(\mathrm{g})$ & 2.04 & $\mathrm{a}$ & 1.96 & $\mathrm{a}$ & 1.20 & $\mathrm{~b}$ & 1.60 & $\mathrm{a}$ \\
\hline
\end{tabular}

was averagely lighter for FI (148g) than for FM (202 g); as expected, this trend was observed also for the average weight of the berry: $1.2 \mathrm{~g}$ for FI versus $1.6 \mathrm{~g}$ for FM. The effect of non-irrigation in post-veraison led therefore to the formation of smaller berries and consequently lighter bunches.

The rainfall in September 2011 (Fig. 2) probably neutralized the effect of post-veraison irrigation: in this vintage no differences in the grapes production per vine were found between the theses. Conversely, in 2012 it was possible to fully test the beneficial effect of postveraison irrigation on grape production capacity since the total rainfall in the ripening period (August-September) did not reach $20 \mathrm{~mm}$ (Fig. 2). It was therefore verified that the prolonged water supply until maturation (FM) allowed to obtain heavier berries and clusters.

Table 2 shows the physicochemical composition of the FM and FI wines. The main difference in the chemical characteristics between FM and FI concerned the alcohol content, significantly higher in FM. On the contrary, no significant differences were observed for the acidic profile, but the FI wines had an averagely lower $\mathrm{pH}$ and an averagely higher titratable acidity than those of the FM thesis. 
Table 2. Physicochemical composition of the FM and FI wines as mean values of the 2011 and 2012 vintages.

\begin{tabular}{l|ccc}
\hline & FM & FI & Sig. \\
\hline alcohol \%Vol & 16.01 & 14.72 & $*$ \\
dry extract (g/L) & 37.5 & 35.93 & $\mathrm{~ns}$ \\
$\mathrm{pH}$ & 3.57 & 3.51 & $\mathrm{~ns}$ \\
titratable acidity (g/L) & 5.74 & 6.04 & $\mathrm{~ns}$ \\
titratable acidity (g/L) & 5.74 & 6.04 & $\mathrm{~ns}$ \\
malic acid (g/L) & 0.96 & 0.33 & $\mathrm{~ns}$ \\
lactic acid (g/L) & 0.45 & 1.47 & $\mathrm{~ns}$ \\
monomer anthocyanins, MA (mg/L) & 21 & 10 & $*$ \\
total anthocyanins, TA (mg/L) & 89.0 & 79.0 & $\mathrm{~ns}$ \\
MA/TA & 0.23 & 0.13 & $* *$ \\
A420/A520 & 1.04 & 1.01 & $\mathrm{~ns}$ \\
A420+A520 & 0.5 & 0.63 & $\mathrm{~ns}$ \\
total flavonoids (mg/L) & 3217 & 3469 & $\mathrm{~ns}$ \\
proanthocyanidins, P (mg/L) & 5335 & 6714 & $*$ \\
flavans reactive with vanillin, V (mg/L) & 2825 & 3253 & $\mathrm{~ns}$ \\
V/P & 0.53 & 0.49 & $\mathrm{~ns}$ \\
\hline *, **, and n.s. represent significance at $p \leq 0.05,0.01$, and & not \\
significant, respectively.
\end{tabular}

Table 3. Composition of condensed tannins in the FM and FI wines as mean values of the 2011 and 2012 vintages.

\begin{tabular}{l|cccc}
\hline & FM & FI & F & Sig. \\
\hline mDP & 8.9 & 8.5 & 40.2 & $* * *$ \\
$\%$ gallates & 4.3 & 4.2 & 14.5 & $* *$ \\
$\%$ EGC & 13.8 & 12.4 & 35.7 & $* * *$ \\
$\%$ EC & 73.4 & 73.5 & 0.1 & n.s. \\
$\%$ C & 26.6 & 26.5 & 0.1 & n.s. \\
tannins mg/L & 1850 & 1879 & 1.8 & n.s. \\
$\%$ EGC-ph & 13.8 & 12.4 & 35.7 & $* * *$ \\
$\%$ C-ph & 19.0 & 18.4 & 2.0 & n.s. \\
$\%$ EC-ph & 52.1 & 53.4 & 59.1 & $* * *$ \\
$\%$ E3Og-ph & 3.6 & 3.7 & 18.7 & $* *$ \\
$\%$ C & 7.5 & 8.1 & 52.9 & $* * *$ \\
$\%$ EC & 3.2 & 3.6 & 900.4 & $* * *$ \\
$\%$ E3Og & 0.7 & 0.5 & 102.7 & $* * *$ \\
\hline \multicolumn{4}{l}{$* * * *$ and n.s. represent significance at $p \leq 0.01,0.001$, and not }
\end{tabular}
significant, respectively.

As regards the polyphenolic profile, FI was distinguished from FM for the higher content in proanthocyanidins (statistically significant differences) and in flavans reactive with vanillin; on the contrary, the FM wines were averagely richer in total and monomer anthocyanins. These results are in agreement with $[15,16]$, as regards in particular the decrease in sugars accumulation and the increase in the synthesis of polyphenolic compounds observed in case of water stress (FI), and with [17], in warm environments of southern Italy in conditions of moderate water stress from veraison to harvest.

Table 3 shows the composition of wines in condensed tannins, determined with the phloroglucinolysis method. Unlike the maceration trials, with which the seeds removal caused a significant decrease of the condensed tannins content, in the case of the irrigation trials the differences did not concern the concentration of these molecules, but
Table 4. Composition in volatile substances of the FM and FI wines as mean values of the 2011 and 2012 vintages.

\begin{tabular}{|c|c|c|c|c|}
\hline & FM & FI & $\mathrm{F}$ & sig. \\
\hline Isoamylacetate & 440 & 249 & 26.24 & $* *$ \\
\hline Ethylhexanoate & 212 & 185 & 7.52 & * \\
\hline 4-methyl-pentanol & 36 & 22 & 41.80 & $* * *$ \\
\hline 3-methyl-pentanol & 71 & 49 & 49.06 & $* * *$ \\
\hline Ethyl lactate (mg/L) & 9.3 & 14.4 & 3.77 & n.s. \\
\hline Hexanol & 459 & 506 & 0.43 & n.s. \\
\hline cis-3-hexenol & 31 & 35 & 4.22 & n.s. \\
\hline trans -2-hexenol & 31 & 45 & 14.83 & $* *$ \\
\hline Ethyl octanoate & 272 & 270 & 0.00 & n.s. \\
\hline Ethyl-3-hydroxybutirrate & 243 & 231 & 0.13 & n.s. \\
\hline Linalool & 10 & 9 & 0.05 & n.s. \\
\hline Isobutyrric acid & 170 & 214 & 1.09 & n.s. \\
\hline$\gamma$-butyrrolactone & 5606 & 5510 & 0.01 & n.s. \\
\hline Butyrric acid & 143 & 132 & 0.06 & n.s. \\
\hline Ethyl decanoate & 123 & 122 & 0.00 & n.s. \\
\hline Isovalerianic acid & 634 & 754 & 0.49 & n.s. \\
\hline Diethylsuccinate & 2320 & 4967 & 44.26 & $* * *$ \\
\hline$\alpha$-terpineol & 11 & 13 & 0.94 & n.s. \\
\hline Methionol & 425 & 399 & 0.22 & n.s. \\
\hline Citronellol & 31 & 19 & 29.12 & $* * *$ \\
\hline Ethyl-4-hydroxybutirrate & 7328 & 7646 & 0.20 & n.s. \\
\hline Hexanoic Acid & 942 & 890 & 4.74 & n.s. \\
\hline Benzylic alcohol & 467 & 529 & 0.97 & n.s. \\
\hline 2-phenylethanol (mg/L) & 53.6 & 49.2 & 0.54 & n.s. \\
\hline Endiol & 50 & 50 & 0.00 & n.s. \\
\hline Diethylmalate & 452 & 436 & 0.03 & n.s. \\
\hline Octanoic acid & 1325 & 1312 & 0.03 & n.s. \\
\hline Diethyl-2-hydroxyglutarate & 198 & 561 & 31.46 & $* * *$ \\
\hline Decanoic acid & 480 & 465 & 0.20 & n.s. \\
\hline Monoethylsuccinate (mg/L) & 42.4 & 61.8 & 4.01 & n.s. \\
\hline Vinylguaiacol & 30 & 33 & 2.09 & n.s. \\
\hline Vanillin & 41 & 56 & 9.18 & $*$ \\
\hline Acetovanillone & 208 & 513 & 20.13 & $* *$ \\
\hline Tirosol & 2621 & 2338 & 0.62 & n.s. \\
\hline
\end{tabular}

$*$ **, ***, and n.s. represent significance at $p \leq 0.05,0.01,0.001$, and not significant, respectively. All data are reported as $\mu \mathrm{g} / \mathrm{L}$ except where indicated.

only their composition, in particular the mean degree of polymerization $(\mathrm{mDP})$ and the percentage of the different monomer units.

The phloroglucinolysis method, used for the characterization of condensed tannins, consists in hydrolyzing flavans in an acidic hot environment. Following the hydrolysis of each flavan composed of $n$ monomer units, 1 flavan-3-ol molecule in the terminal position (terminal unit) and $n-1$ molecules occupying the successive positions (extension units) are released in the wine as carbocations on $\mathrm{C} 4$, which bind to phloroglucinol.

The terminal units found in wines after phloroglucinolysis were $(+)$-catechin $(\mathrm{C}),(-)$-epicatechin $(\mathrm{EC})$, (-)-epicatechin-3-O-gallate $(\mathrm{E} 3 \mathrm{Og})$, while the extension units were (-)-epigallocatechin (EGC-ph), (+)-catechin (C-ph), (-)-epicatechin (EC-ph), (-)-epicatechin-3-Ogallate (E3Og-ph), linked to phloroglucinol (ph). All units 


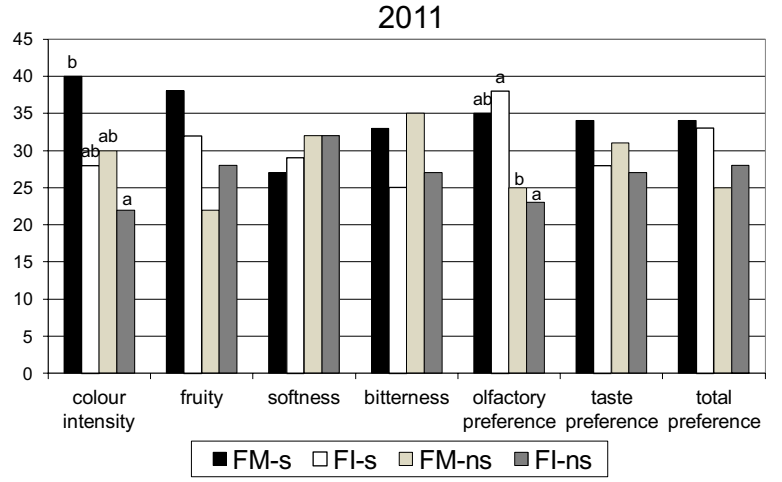

Figure 4. Results of the sensory analysis in 2011. The suffixes -s and -ns indicate respectively the presence or absence of grape seeds during the fermentative maceration.

were quantified by HPLC-DAD (Table 3). Finally, based on the total concentration of the terminal and extension units, it is possible to calculate the mean degree of polymerization $(\mathrm{mDP})$ of the condensed tannins. Table 3 shows that, concentration being equal, the condensed tannins of FM wines had a higher mean degree of polymerization, a higher percentage of galloylated forms and a higher EGC-ph content compared to the FI wines. The total percentage content of $\mathrm{C}$ and $\mathrm{EC}$ was similar in the wines of the two theses, although significant differences were observed when considered separately as terminal units (only for EC) or as extension units (for both C-ph and EC-ph).

Regarding the composition in volatile substances (Table 4), statistically significant differences between the FM and FI theses were observed for some volatile compounds, isoamylacetate and ethylhexanoate among those with fermentative origin, and citronellol among those with varietal origin: FM was distinguished from FI for the major contents of these molecules. From a more general point of view, the FI wines had a higher overall content in aroma compounds (as the sum of all compounds). This result was in agreement with previous research that highlighted how water stress during berry maturation can increase the overall content of wine volatile compounds [6].

As regards the sensory characteristics (Figs. 4 and 5), the wines resulted similar to each other; only during the first year of the trial, the FM wines were significantly distinguished from the corresponding FI wines for the more intense color. The effect of the increase in water intake on the polyphenolic profile was comparable to the effect of seeds removal during fermentative maceration [18].

\section{Conclusions}

The seasons and the climate strongly influenced the composition of grapes and wines. The effect of irrigation on the vegetative-productive activity of the grapes and on their composition was evident despite the influences of the climatic conditions of the vintage. In 2011 the compared theses did not show different production capacities, leading to very similar results. Probably, the more abundant rains of September and October 2011 caused in the FI thesis

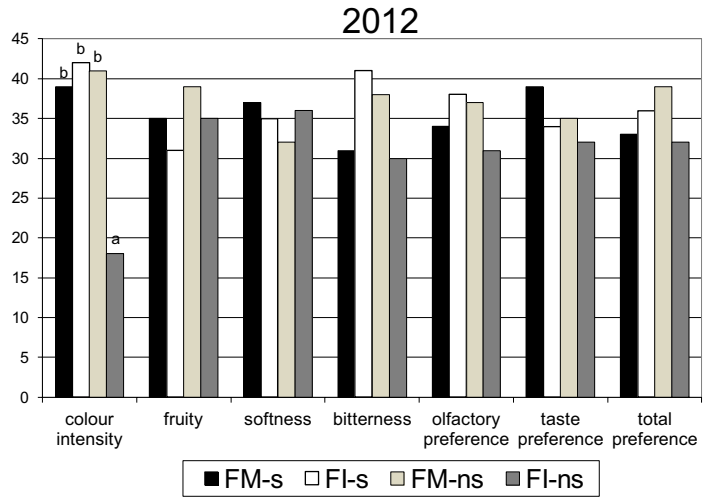

Figure 5. Results of the sensory analysis in 2012. The suffixes -s and -ns indicate respectively the presence or absence of grape seeds during the fermentative maceration.

the same effect of prolonged irrigation until maturation of the FM thesis. In 2012 the FM thesis gave better results, surely due to the condition of lower water stress caused by irrigation, which allowed a better photosynthetic activity that resulted in a higher intrinsic efficiency in the use of water. The same trend was observed for the alcohol content of the wines: the differences in favor of the thesis with higher water inputs (FM) were more evident in the 2012 harvest. On the contrary, the loss of polyphenolic compounds (particularly proanthocyanidins) with the increase of water intake was evident in both vintages.

\section{References}

[1] G. Maracchi, O.M.B. Sirotenko, Clim. Chang. 70, 117 (2005)

[2] H. Gitay, A. Suarez, R.T. Watson, D.J. Dokken, Climate Change and Biodiversity. Intergovernmental Panel on Climate Change - IPCC Technical Paper V (Geneva, Switzerland, April 2002)

[3] ISMEA - IAMB, Cambiamenti Climatici e Risorse Idriche Nella Regione Mediterranea. Le Nuove Sfide per L'agricoltura. Osservatorio permanente sul sistema agro-alimentare dei paesi del Mediterraneo (2009)

[4] G.V. Jones, M.A. White, O.R. Cooper, K. Storchmann, Clim. Chang. 73, 319 (2005)

[5] J. Cifre, J. Bota, J.M. Escalona, H. Medrano, J. Flexas, Agric. Ecosyst. Environ. 106, 159 (2005)

[6] M.M. Chaves, O. Zarrouk, R. Francisco, J.M. Costa, T. Santos, A.P. Regalado, M.L. Rodrigues, C.M. Lopes, Ann. Bot. 105, 661 (2010)

[7] F. Mannini, A. Schneider, G. Gambino, P. Boccacci, D. Santini, W. Chitarra, I. Perrone, D. Lanati, D. Marchi, Studio per L'individuazione Dei Portinnesti più Adatti Alla Coltivazione Del Gaglioppo (Rubbettino Editore, 2015)

[8] A. Bosso, M. Guaita, L. Panero, D. Borsa, R. Follis, Am. J. Enol. Vitic. 60, 379 (2009)

[9] Commission Regulation (EEC) No. 2676/90 determining Community methods for the analysis of wines, 1-192 (1990)

[10] P. Cane, Enotecnico 26, 69 (1990) 
[11] R. Di Stefano, M.C. Cravero, N. Gentilini, Enotecnico 25, 83 (1989)

[12] J.A. Kennedy, G.P. Jones, J. Agric. Food Chem. 49, 1740 (2001)

[13] M.A. Ducasse, R.M. Canal-Llauberes, M.D. Lumley, P. Williams, J.M. Souquet, H. Fulcrand, Food Chem. 118, 369 (2010)

[14] X. Choné, C. van Leeuwen, D. Dubourdieu, J.P. Gaudillère, Ann. Bot. 87, 477 (2001)

[15] C. van Leeuwen, A. Destrac-Irvine, OENO One 51, 147 (2017)
[16] E. Bahar, A. Carbonneau, I. Korkutal, Vine and Berry Responses to Severe Water Stress in Different Stages in cv. Syrah (Vitis vinifera L.). The Special Issue of 2nd International Balkan Agriculture Congress May 16-18, 2017 - Tekirdag, Turkey

[17] S. Poni, A. Palliotti, G. Mattii, R. Di Lorenzo, Italus Hortus 14, 29 (2007)

[18] M. Guaita, M. Petrozziello, L. Panero, C. Tsolakis, S. Motta, A. Bosso, Eur. Food Res. Technol. 243, 1311 (2017) 